\title{
Encarsia Wasp, a Silverleaf Whitefly Parasitoid (suggested) Encarsia formosa Gahan (Insecta: Hymenoptera: Aphelinidae) ${ }^{1}$
}

\author{
Erich N. Schoeller, Vivek Kumar, Cindy L. McKenzie, and Lance S. Osborne ${ }^{2}$
}

The Featured Creatures collection provides in-depth profiles of insects, nematodes, arachnids and other organisms relevant to Florida. These profiles are intended for the use of interested laypersons with some knowledge of biology as well as academic audiences.

\section{Introduction}

Encarsia formosa Gahan (Hymenoptera: Aphelinidae) (Figure 1) is a small, parasitoid wasp that attacks several species of whiteflies. It is one of the most commercialized natural enemies and used worldwide in controlled production systems (greenhouses and nurseries) for biological control of whiteflies on ornamentals and vegetables (Hoddle et al. 1998). The earliest record of E. formosa parasitic activity was observed in 1926, when an English tomato grower observed black pupae among greenhouse whitefly pupae, Trialeurodes vaporariorum Westwood (Hemiptera: Aleyrodidae) on the leaves (Figure 2) and over time observed $E$. formosa emerging from these pupae.

In England, E. formosa was first used commercially a year later to control T. vaporariorum in hothouses (Speyer 1927), and by the 1930's, E. formosa hademerged as a successful commercialized natural enemy for whiteflies and was sold to nurseries both within and outside of Europe (Van
Lenteren and Woets 1988). With the growing popularity of synthetic chemical insecticides after World War II, biological control methods became less common, and the demand for the parasitic wasps declined substantially. However, reports of insecticide resistance development among pest insects in the following decades brought biological control methods back into vogue.

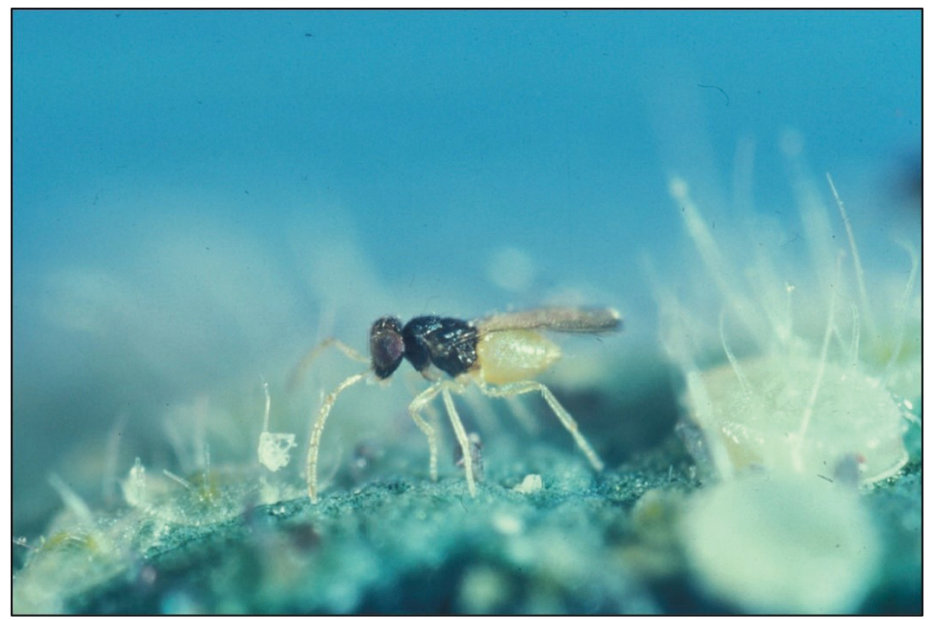

Figure 1. Encarsia formosa adult searching for a host. Credits: Lance S. Osborne, UF/IFAS

1. This document is EENY-771, one of a series of the Entomology and Nematology Department, UF/IFAS Extension. Original publication date April 2021. Visit the EDIS website at https://edis.ifas.ufl.edu for the currently supported version of this publication. This document is also available on the Featured Creatures website at http://entnemdept.ufl.edu/creatures/.

2. Erich N. Schoeller, Entomology and Nematology Department; Vivek Kumar, Entomology and Nematology Department; Cindy L. McKenzie, United States Horticulture Research laboratory, ARS-USDA; and Lance S. Osborne, Entomology and Nematology Department; UF/IFAS Extension, Gainesville, FL 32611.

The Institute of Food and Agricultural Sciences (IFAS) is an Equal Opportunity Institution authorized to provide research, educational information and other services

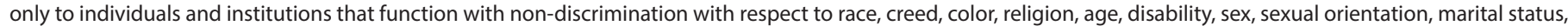

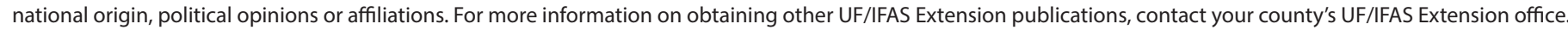
U.S. Department of Agriculture, UF/IFAS Extension Service, University of Florida, IFAS, Florida A \& M University Cooperative Extension Program, and Boards of County Commissioners Cooperating. Nick T. Place, dean for UF/IFAS Extension. 


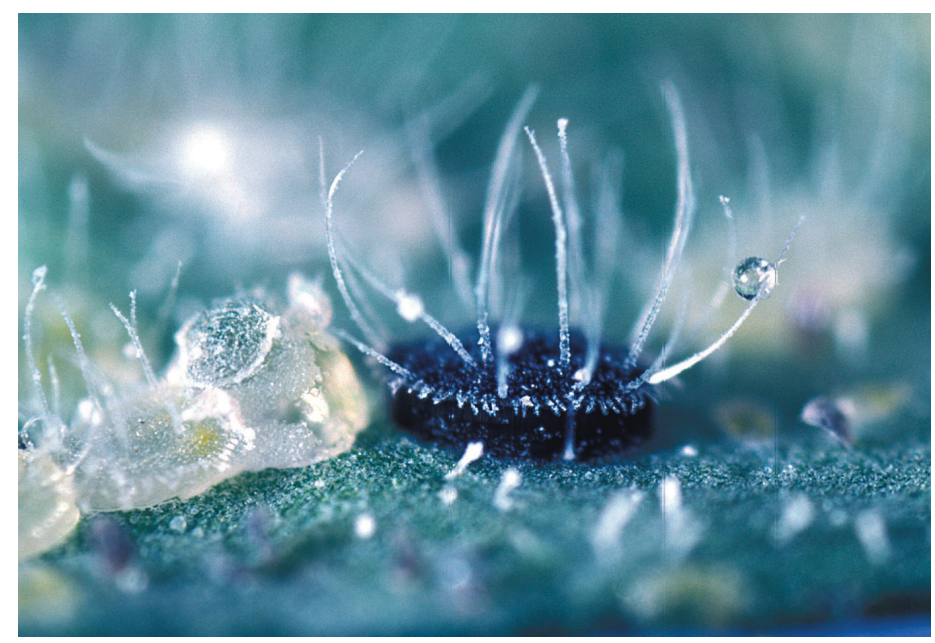

Figure 2. Whitefly Bemisia tabaci nymph parasitized by Encarsia formosa wasp.

Credits: Lance S. Osborne, UF/IFAS

\section{Distribution}

Encarsia formosa is a cosmopolitan parasitoid with an ambiguous native range (Hoddle et al. 1998). Its similarity to Encarsia luteola Howard suggests that this species first emerged in the Western Hemisphere (Hoddle et al. 1998; Polaszek et al. 1992). Current records of its greenhouse usage show that it is widely utilized in various parts of Europe and Russia, and there are excellent prospects for its use in greenhouse production systems in North America and Asia as well, where this species is currently underutilized.

\section{Description}

Encarsia formosa is a thelytokous species, where females develop from unfertilized eggs. Males exist but are rare and emerge concurrently with their female counterparts as primary parasitoids. Thelytoky in E. formosa is mediated by Wolbachia (a genus of sex-determining intracellular bacteria) infections, and while $E$. formosa exhibits mating behavior and males produce sperm, females are unable to be properly inseminated and thus cannot reproduce sexually (Zchori-Fein et al. 1992). Females are typically $\sim 0.6 \mathrm{~mm}$ long by $0.3 \mathrm{~mm}$ wide, with a black head and thorax and a yellow abdomen (Figure 1). Males are dark in color and may also occur rarely as autoparasites (parasitic on their own species) of female Encarsia formosa larvae (Gerling 1966).

Adult E. formosa kills its hosts not only by parasitizing the immature stages but also via host feeding (Dai et al. 2012). Adult E. formosa feed on immature whiteflies by piercing the host's cuticle with their ovipositor (Figure 3) and then consuming the hemolymph through the wound (Figure 4) ultimately killing the host. Although E. formosa feeds on all the immature whitefly stages except the eggs, their preferred host stage may vary depending upon prey species. Pupae and $2^{\text {nd }}$ instar nymphs of $T$. vaporariorum are the preferred stage for feeding, whereas in Bemisia tabaci Gennadiusthe pupae and nymphal instars are equally preferred (Hoddle et al. 1998). The size of the adult parasitoid has not been shown to vary by the host stage parasitized but may influence immature development time (Hu et al. 2003). Adult female E. formosa oviposit (lay eggs) singly into the sessile immature stages (older than crawler stage) of $B$. tabaci, but prefer to parasitize the $3^{\text {rd }}, 4^{\text {th }}$ and pre-pupal nymphal stages. The most reliable sign of a parasitized $T$. vaporariorum nymph is the change in color from clear or translucent to black, which occurs about two weeks after parasitism. This dramatic color change does not occur in parasitized B. tabaci. Whitefly nymphs which have been previously probed for feeding are not used for parasitism and vice-versa (Hoddle et al. 1998).

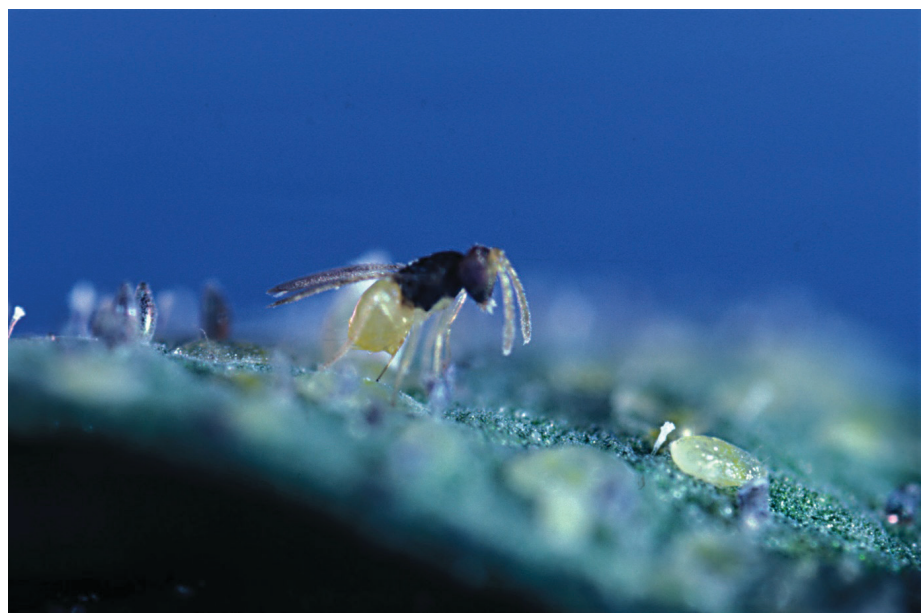

Figure 3. Encarsia formosa adult female inserting its ovipositor in a whitefly nymph.

Credits: Lance S. Osborne, UF/IFAS

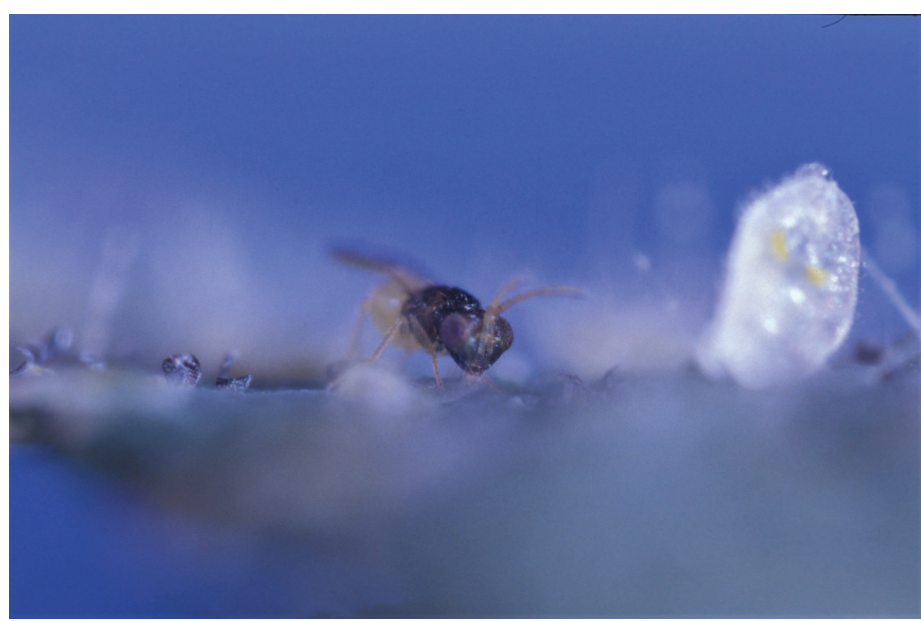

Figure 4. Host feeding of a Bemisia tabaci nymph by an adult Encarsia formosa.

Credits: Lance S. Osborne, UF/IFAS 


\section{Biology}

Female E. formosa find suitable hosts for oviposition via fly-and-walk sequences or "roaming", which is mediated by complex visual and chemical cues (Guerrieri 1997). Female E. formosa lay 8-10 eggs per day, although this rate slows as the females age. Females lay a single egg per whitefly. On $B$. tabaci, it was found that E. formosa larval development times varied based on the prey instar parasitized, and their development time was less when parasitizing older instars (Hu et al. 2003; Liu et al. 2016). Depending on the prey species, host plant, and the whitefly instar parasitized, development from embryo to adult can take 14 - 25 days (Hoddle et al. 1998; Hu et al. 2003). Environmental temperature can greatly influence their life cycle parameters; for instance at $30^{\circ} \mathrm{C}$, developmental time from egg to adult can take about 10 days; however, at $18^{\circ} \mathrm{C}$ it can take as long as 40 days (Osborne and Ehler 1981). The optimal temperature for development and parasitism rates is about $27^{\circ} \mathrm{C}$. Encarsia formosa females live for approximately 12 days and can lay 59 eggs during this time with $T$. vaporariorum as a host (Hoddle et al. 1998).

\section{Hosts}

Information on Encarsia formosa habitat and associated plants is restricted almost exclusively to greenhouse settings. Economically important crops on which this parasitoidis mostly used are as follows: tomato, cucumber, eggplant, cotton, tobacco, strawberry, and poinsettia (Hoddle et al. 1998). Encarsia formosa can attack $>15$ species of whitefly among which T. vaporiorum and $B$. tabaci are of the greatest economic concern to the greenhouse producers. Encarsia formosa has also been observed parasitizing other whitefly species including solanum whitefly (Aleurotrachelus trachoides Back), honeysuckle whitefly (Aleyrodes lonicerae Walker), cabbage whitefly (Aleyrodes proletella $\mathrm{L}$ ), iris whitefly (Aleyrodes spiraeoides Quaintance), citrus whitefly (Dialeurodes citri Ashmead), Aleuroglandulus malangae Russelland Dialeurodes chittenden Laing (Polaszek et al. 1992).

\section{Economic Importance}

During their lifespan, adult Encarsia formosa can kill about 95 T. vaporiorum nymphs by ovipositing an average of five eggs per day and feeding on three nymphs per day (Hoddle et al. 1998). A recent study suggested E. formosa can consume approximately ten $1^{\text {st }}-2^{\text {nd }}$ instar, or five $3^{\text {rd }}-4^{\text {th }}$ instar B. tabaci over a 48 hour period (Zang and Liu 2008), and their host feeding potential can be enhanced by depriving them of food before release (Zang and Liu 2010).
Depending upon the target crop, E. formosa can be commercially applied in greenhouses using inundative (mass release of natural enemies for immediate pest control, where establishment is not expected) or inoculative (small releases made when pest populations are low and natural enemies are expected to establish) release strategies. In commercial ornamental production where there are low whitefly damage thresholds and a zero-tolerance policy for items to be exported, inundative releases of E. formosa are considered the preferred mode for whitefly control. The inoculative releases of $E$. formosa can be done by any of the methods tested in the past, which include the "pest in first approach" and "dribble method." As the name suggests, "the pest in first approach" method involves releasing adult whiteflies into the greenhouse before releasing $E$. formosa. The objective here is the successful establishment of the parasitic wasp population in the production system. However, for obvious reasons of needing to release pests into the production system, this method is not widely employed by the growers. The "dribble method" involves releasing E. formosa at low rates in anticipation of an arriving whitefly population whichwill continue until parasitized black whitefly nymphs are observed.

It is difficult to make a general recommendation on the number of parasitoids needed to be released by growers for effective whitefly control, as it depends on many factors including target host plants, greenhouse temperature, whitefly species, and the level of whitefly infestations (Osborne and Ehler 1981). However, depending upon the availability of parasitoids and the cost of their release, it would be best to release an equal number of parasitoids for each whitefly adult. It is worth mentioning that since most of the chemical insecticides can have a negative impact on E. formosa populations, parasitoids should be released at least two weeks post application of the insecticides. For optimal results, it is important to follow general cultural practices such as removal of alternate hosts (weeds, plants, cuttings) of the whiteflies from the greenhouse before releasing parasitoids. In the United States, Encarsia formosa is commercially sold by multiple vendors of beneficial organisms.

\section{Selected References}

Dai P, Ruan C, Zang L, Wan F, Liu L. 2014. Effects of rearing host species on the host-feeding capacity and parasitism of the whitefly parasitoid Encarsia formosa. Journal of Insect Science 14:118. 
Gerling D. 1966. Biological studies on Encarsia formosa (Hymenoptera: Aphelinidae). Annals of the Entomological Society of America 59: 142-143.

Guerrieri E. 1997. Flight behaviour of Encarsia formosa in response to plant and host stimuli. Entomologia Experimentalis et Applicata 82: 129-133.

Hoddle MS, Van Driesche RG, Sanderson JP. 1998. Biology and use of the whitefly parasitoid Encarsia formosa. Annual Review of Entomology 43: 645-69.

Hu JS, Gelman DB, Blackburn MB. 2003. Age-specific interaction between the parasitoid, Encarsia formosa and its host, the silverleaf whitefly, Bemisia tabaci (Strain B). Journal of Insect Science, 3: 28. https://doi.org/10.1093/ jis/3.1.28

Liu X, Zhang Y, Xie W, Wu Q, Wang S. 2016. The suitability of biotypes Q and B of Bemisia tabaci (Gennadius) (Hemiptera: Aleyrodidae) at different nymphal instars as hosts for Encarsia formosa Gahan (Hymenoptera: Aphelinidae). PeerJ. 4:e1863.

Osborne LS, Ehler LE. 1981. Biological control of greenhouse whitefly in California greenhouses. Leaflet 21260. Cooperative Extension, US. Department of Agriculture, University of California.

Polaszek A, Evans GA, Bennet FD. 1992. Encarsia parasitoids of Bemisia tabaci (Hymenoptera: Aphelinidae, Homoptera: Aleyrodidae): a preliminary guide to identification. Bulletin of Entomological Research 82: 375-392.

Speyer ER. 1927. An important parasite of the greenhouse whitefly (Trialeurodes vaporariorum Westwood). Bulletin of Entomological Research 17: 301-308.

Van Lenteren JC, Woets J van. 1988. Biological and integrated pest control in greenhouses. Annual Review of Entomology 33: 239-269.

Zang LS, Liu TX. 2008. Host feeding of three whitefly parasitoid species on Bemisia tabaci B biotype, with implication for whitefly biological control. Entomologia Experimentalis Applicata 127: 55-63.

Zang LS, Liu TX. 2010. Effects of food deprivation on host feeding and parasitism of whitefly parasitoids. Environmental Entomology 39: 912-918.
Zchori-Fein E, Roush R T, Hunter MS. 1992. Male production induced by antibiotic treatment in Encarsia formosa (Hymenoptera: Aphelinidae), an asexual species. Experientia 48: 102-105. 